\title{
The influence of smartphones' operation modes on the superficial temperature distribution in the human auricle region
}

\author{
A small-scale $(n=20)$ clinical examination
}

\author{
Joanna Bauer ${ }^{1} \cdot$ Ignacy Górecki $^{1} \cdot$ Maria Kohyt $^{1} \cdot$ Agnieszka Migasiewicz $^{2} \cdot$ Halina Podbielska $^{1}$
}

Received: 15 August 2017 / Accepted: 28 January 2018/ Published online: 7 February 2018

(C) The Author(s) 2018. This article is an open access publication

\begin{abstract}
In this study, the infrared thermography was used to examine heating effects in human auricle region due to short-duration use of smartphones in normal and flight mode operation by 20 healthy volunteers (age 19-24 years, 9 females and 11 males). Statistically significant differences in both modes were observed between mean temperatures of the auricle regions before and immediately after the use of the smartphone. The increase in tissue temperature resulted from a combined effect of conductive heat transfer caused by the non-microwave-related activity of the smartphone and the absorption of the radiofrequency microwaves. Furthermore, we observed the thermal effect even after $1 \mathrm{~h}$ of such short use of the smartphone. The transient temperature change in tissues due to smartphone use can contribute to the cumulative thermal effects and thus both short- and long-duration use of smartphones should be considered in future studies. The small study also showed a gender dimension in the thermal response, which also merits further investigation. The study confirmed the usefulness of using thermography for direct quantitative analyses of temperature changes related to smartphone usage, which can be exploited in future epidemiological studies in personalized and preventive medicine.
\end{abstract}

Keywords Infrared thermography $\cdot$ Personalized medicine $\cdot$ Preventive medicine $\cdot$ Mobile phones $\cdot$ Smartphones $\cdot$ Radiofrequency radiation

\section{Introduction}

Cordless telephones, popularly known as mobile phones, have become the dominant tool for mass communication in the last few decades. It is estimated that in 2017 there are nearly 4.5 billion mobile phones users worldwide, which represents almost $60 \%$ of the total global population. The number of mobile phone users is expected to grow to nearly 4.8 billion in 2020 [1]. There is a plethora of mobile

Joanna Bauer

joanna.bauer@pwr.edu.pl

1 Department of Biomedical Engineering, Faculty of Fundamental Problems of Technology, Wrocław University of Science and Technology, Wybrzeże Wyspiańskiego 27, 50-370 Wrocław, Poland

2 Department of Cosmetology, Faculty of Physiotherapy, Wrocław University School of Physical Education, Al. Paderewskiego 35, 51-612 Wrocław, Poland phone types in use. For example, the so-called smartphones that combine features of conventional phones and personal computers in one handheld 'smart' device are now the most dominant type of mobile phones used in developed countries. Nearly $80 \%$ mobile phone users in the North America and over $70 \%$ mobile phone users in the Western Europe would carry smartphones in the last quarter of 2016 [1]. By the year 2020, the proportion of smartphone users in these regions is expected to reach between 80 and $90 \%$. The global trend is similar to this trend with an increased number of users switching to smartphones for their telephone, communication, business, entertainment, navigation, education, internet browsing, and computing needs. On most occasions, a user would hold the phone against the one of the ears of the user for the duration of the use. This practice can give rise to temperature in the area surrounding the ear. In this study, we present the results of a small-scale $(n=20$ volunteers $)$ trial of the superficial 
temperature distribution in the auricle region caused by the use of smartphones in normal (on-communication) and flight (off-communication) operation modes.

Smartphones, similar to any other mobile phone, use cell phone network technology to send and receive data as radio signals. The frequency used typically falls within the microwave range $(300 \mathrm{MHz}-300 \mathrm{GHz})$, of which two specific bands, namely 850-900 MHz and 1800-1900 MHz, are used for third/fourth generation (3G/4G) networks depending on the geographic location of the use. The superior data handling and outstanding multimedia capability of smartphones have made these phones to become an integral part of lifestyle choice. This gives rise to concerns about the users' health due to exposure to microwave, which, similar to any other electromagnetic radiation (EMR), leads to both thermal and non-thermal impacts on living organisms.

The health hazard associated with prolonged use of mobile phones ( $>10$ years) has been discussed in the literature with somewhat confusing, if not contradictory, conclusions. Below, we provided a short, non-exhaustive summary of the literature that studied such hazard. Many of these studies indicate a positive correlation between the exposure to radiofrequency $(3 \mathrm{kHz}-300 \mathrm{GHz})$ on living organisms including human and a higher risk of developing some pathologies. Paradoxically, there are also many studies, which conclude with opposite results.

Mobile phones have generally a dual influence on human tissues, which correspond to the thermal and nonthermal effects. Non-thermal effects include the interactions of both magnetic and electrical fields. The magnetic field is more influential than the electric field in penetrating human body through skin [2] and is connected with the magnetic permeability of different tissues and organs [3]. Both magnetic and electric fields can induce alternating currents inside the living organisms that may cause the negative physiological effects on tissue, cellular or subcellular levels. At the tissue level, the response to electromagnetic field can vary due to the specific anatomical and chemical structure as well as electrical properties of tissues such as the electric permittivity and conductivity [3]. Skin, bone, blood, muscles, epithelial or neural tissues absorb radiofrequency radiation in different ways and with different speeds $[4,5]$. At cellular and subcellular levels, it was shown that EMR, including microwaves used in telecommunication, can cause changes in plasma membrane structure and functionality [6, 7], DNA damage [8-10], cell enzymes activation/deactivation, for example, intracellular lysosomes [11, 12] or histone kinase [13], cellular proteins alternation and conformation changes, for example, heat shock protein $70 \mathrm{hsp}$ [14], as well as calcium-potassium ions efflux $[15,16]$.

Thermal effects are considered as principal factors affecting physiological processes in human body due to heat conduction to other tissues, convection through blood perfusion, and radiation to the surrounding tissues [3, 17, 18]. The effect of heat on living objects is not always uniform and is dependent on the intensity of heat stimulus, stimulus duration, and the external environment of stimulation [19]. The generation of heat in human tissues from the absorption of high-frequency electromagnetic waves is caused by an enhanced electrical conductivity of the tissue [17]. Heat accumulates in tissues as well due to an imbalance between the heat generation and heat dispersion. Thermal effects may cause disruption of cell functions and development. To summarize, the general consensus in the literature is that the risks of thermal impact of mobile phones on living organisms outweigh the non-thermal effects, for example, those from the dipole polarization of biomolecules and tissues, which are known to be electrically active and polarizable [20, 21].

Efforts in the direct measurement of thermal changes caused by mobile phones are seldom reported. Tahvanainen et al. [22] used negative temperature coefficient (NTC) thermistors to directly measure ear canal temperature during and after mobile phone usage at frequency 900 and $1800 \mathrm{MHz}$ by human volunteers $(n=30)$. Kargel [23] have used infrared thermography for quantitative analysis of local heating in ears caused by mobile phones operating at $1800 \mathrm{MHz}$ with two different specific absorption rate (SAR) values (0.39 and $\left.1.26 \mathrm{~W} \mathrm{~kg}^{-1}\right)$. Lahiri et al. [24] have also used IR thermography to measure thermal change in both contact and non-contact use of mobile phones (operating at $900 \mathrm{MHz}$ ) for human volunteers $(n=5)$.

Thermal effects have been discussed in the historical literature on the health impact of mobile phone use. Most investigators, however, focused on the final manifestation of pathology rather than the cause and the pathway of the pathology owing to the thermal effect caused by the exposure. Recent large clinical data, on the other hand, emphasize the cumulative nature of the exposure toward pathogenesis [25]. This has inspired us to investigate, both directly and quantitatively, how the usage of smartphones can heat up the anatomical part in contact and how in over the years such heat can accumulate to a pathological development such as brain tumors, ischemia, or a loss of hearing.

As it has been stated before, there are many contradictory results reported on potential carcinogenic effects of cellular phones, for example, in malignant brain tumors such as glioma, meningioma, acoustic neuroma, or astrocytoma. Dreyer et al. [26] conducted a large cohort study of 300,000 cellular handheld and non-handheld telephone users, identified from telephone billing records and death cause data from the National Death Index, and did not find an increased risk of brain tumors or leukemia with longer 
use of mobile phones. Schüz et al. [27] also did not find any strong link between the usage of mobile phone and enlarged risk of cancer in a study that was carried out involving 420,000 Danish citizens. Similarly, no evidence was found that showed mobile phone use had influenced the incidence of cancers in brain or other nervous system cancers in 35,250 glioma cases in Nordic countries [28] and 24,813 USA citizens [29]. These studies contradict previous studies such as those made by Schoemaker et al. [30] on 678 patients (vs. 3553 control patients) and Hepworth et al. [31] on 966 patients (vs. 1716 control), or that of Khurana et al. [25]. The latter study provides a meta-analysis of 11 long-term, case-controlled epidemiologic data that associated ipsilateral (one ear had been used during conversations) mobile phone use with higher risk of a tumor in case of $>10$ years' phone usage. Even more recent studies such as that by Prasad et al. [32] link mobile phone use with significantly higher risk of brain tumors especially among the long-term users ( $\geq 10$ years). Among the 22 case control studies that underwent meta-analyses, the authors have found that 'higher quality' studies showed a positive correlation (higher risk) while 'lower quality' studies showed a negative correlation (lower risk) toward increased risk of the occurrence of brain tumor. International Agency for Research on Cancer (IARC) based on these reports has classified mobile phone radiation as "possibly carcinogenic to humans" (group 2B on the IARC scale) [33].

There is, however, a general agreement in the literature on the effect of mobile phones on cognitive and comfort response of the users [34]. Some neuropsychiatric disorders such as headaches, memory alterations, dizziness, tremors, depressive symptoms, and sleep disturbances were significantly higher among inhabitants exposed to radiofrequency EMR emitted from mobile phone base station antennas [35]. Some of the cognitive functions showed a decrease in men subjected to mobile phone radiation [36, 37], and electroencephalograph (EEG) patterns could change, for example, for auditory and visual memory tasks $[38,39]$. There are reports of waking up of subjects after sleep onset in the non-rapid eye movement (REM) phase when exposed to pulse-modulated microwave radiations $[40,41]$ and a shortening of sleep onset latency as well as reduction in duration and percentage of REM sleep phase [42]. Regular mobile phone usage has been linked to attention deficiency, increased fatigue, irritability, anger or anxiety and sensations such as tingling, numbness of exposed tissue, or ear burning [43, 44], phantom vibrations, and ringing syndrome [45].

It is also generally agreed in the literature that children including fetuses are a in high-risk group, because their higher tissue conductivity and thinner skull bone increase vulnerability to electromagnetic radiations emitted from the cell phones more than in the adults [46, 47]. Negative impacts on male fertility including sperm count, morphology, motility, and viability were also observed when reproductive organs or semen were exposed to radiofrequency waves for an extended period [48]. Furthermore, mobile phone radiations may alter cellular functions leading to decreased male hormone secretion and altered cell proliferation during reproduction process [17].

Due to the cumulative nature of health hazards associated with microwave exposure, the usage pattern as well as the duration and frequency of use of microwave devices must be considered. Users of smartphones can be considered to be at the risk of higher level of radiation exposure than the subjects of conventional mobile phone users in the literature. This is because smartphone usage includes far more activities than simple mobile phone use for telephone conversations only. Most of the historic studies discussing risks associated with mobile phone usage are thus inadequate when dealing with the risks associated with smartphone use. In many of these studies, the wavelengths used did not always correspond to the specific wavelengths used in mobile communications (e.g., $850-900 \mathrm{MHz}$ or $1800-1900 \mathrm{MHz}$ band). The exposure evaluation often relied on self-administered questionnaires or reports from the telephone companies rather than direct measurements of exposure and radiation effect. There is also a lack of harmony across the parameters used in study conditions. For example, exposure had been defined in terms of either semi-quantitative parameters such as weekly or daily use of mobile phones, latency period since first use such as longor short-term usage, or less-specific lifetime use such as cumulative lifetime use in hours or cumulative number of calls. On the other hand, smartphones generally have much lower specific absorption rates (SAR) and much higher battery capacity in comparison with the older mobile phones. While a low SAR means lower radiofrequency absorption for the user, it is not known how the increased frequency of use of smartphone and the resulting Joule heating from the concomitant battery use would transfer in tissue heating.

We addressed this question by using two operation modes typically available in smartphones: the normal mode operation, where both microwave communication and basic non-microwave mobile phone activity take place, and the so-called flight mode operation, where only the nonmicrowave activity exists. In this study, the thermal effects of Samsung S3 smartphone usage on human auricle region were examined. This allowed us to check whether the phone calls change the superficial distribution and the persistence of the auricle temperature for a given usage time. The study also allowed quantifying the contribution of battery activity versus radiofrequency signal transmission/wireless activity in the auricle superficial temperature 
change. We also investigated, albeit to a limited extent, the gender dimension of these effects.

\section{Materials and methods}

In order to conduct the study that involved human volunteers, the approval of the Senate Ethics Committee for Scientific Research at the University School of Physical Education in Wroclaw was obtained. The experimental group consisted of 20 healthy volunteers aged 19-24 (mean age $22.1 \pm 1.1$, including nine women and 11 men. All participants were informed a priori about the details of the experiment, and they all consented to participate in the planned research.

Temperature measurements were conducted by use of thermal imaging camera FLIR T335 (operation range $7.5-13 \mu \mathrm{m}$, focal plane array of $320 \times 240$ uncooled microbolometers, thermal sensitivity $50 \mathrm{mK}$ at $30^{\circ} \mathrm{C}$ ). Each participant was adapted to the ambient conditions for a period of $20 \mathrm{~min}$ before thermal images recording. Experimental conditions (such as the room size, humidity, ambient temperature, etc.) were controlled following the guidelines for thermographic measurements in medical applications given by the European Association of Thermology [49]. Thermography is well known and scientifically approved method of temperature distribution measurements in medicine and physiotherapy [50] and thus often used for screen tests [51, 52], early diagnosis [53, 54], or treatment personalization [19, 55] etc.

A Samsung Galaxy S3 smartphone (operating at a frequency of $900 \mathrm{MHz}$ ) was used throughout the study. This smartphone was chosen due to the dominant presence of Samsung in the global market of smartphones. For example, in 2016, Samsung possessed the largest share of smartphone market with an approximately $22.3 \%$ of the global sale. It was ahead of Apple (12.9\%) and other brands such as Huawei, Oppo, and Xiaomi [1]. Two phone modes were tested-normal mode (full connection with GSM net, battery runs in full mode) and flight mode (no connection with GSM net, switched off all wireless activity, battery runs in saving mode). The detailed technical specification of the phone can be found in the Table 1 .

At the beginning of the experiment, volunteers were asked which mode of use they would prefer (contact or non-contact with ear). Volunteers who chose the contact mode had participated in the study. The volunteers kept the phone in contact with the ear during the duration of the phone call. They were informed about the mode of operation of the phone, i.e., when it was switched on, switched off, or was in the flight mode.

It is possible that the volunteers can apply gentle pressure to overcompensate for their involuntary movements and some heat conduction could occur. To quantify the amount of temperature rise due to such activities, we conducted another small study involving ten volunteers (five male and five female) who used the phone keeping in contact with the ear in the same manner to if they were using the phone. However, the mobile phone was switched off. This allowed us to find the temperature changes due to holding the phone in contact with ear for the duration of the call. The mean temperature of the ear changed by $\sim 0.12 \pm 0.08{ }^{\circ} \mathrm{C}$ during such usage of phone. The thermal effect disappeared after around $10 \mathrm{~min}$. We did not study the gender dimension there.

For each volunteer, eight thermal images were taken: before the experiment, immediately after a phone call of 5 min duration, and then after every $10 \mathrm{~min}$ for $1 \mathrm{~h}$ after the original phone call was made. Altogether, a database of 320 thermal images ( 2 operation modes $\times 20$ volunteers $\times 8$ experimental thermal images) was recorded and analyzed.

The thermal data were first analyzed by using ThermaCAM Researcher Pro 2.10 software. As a region of interest (ROI), the auricle region was chosen, and for each image, the mean temperature was determined by the software (see Fig. 1)

In the next step, the full statistical analysis was carried out using IBM SPSS Statistic version 23.0.0.0 [56]. First, the Kolmogorov-Smirnov tests were applied to check whether the data were significantly drawn from a normally distributed population at a significance level, $\alpha=0.05$. Then, Student's $t$ tests were carried out for the whole population to check whether the $5 \mathrm{~min}$ phone calls change the superficial distribution of the temperature of the auricle and how long the potential thermal effect lasts. Two alternative phone modes (normal vs. flight) were analyzed.

In the last step, Student's $t$ tests were carried out for two segregated subpopulations (women vs. men) to check whether the temperature changes are dependent on phone callers' gender.

\section{Results and discussion}

\section{IR thermography of auricle region temperature change after a short call (5 min)}

Figure 2 shows the distribution of temperature increase observed in the auricle region of each volunteer immediately after a 5 min phone call in both operational modes used in the present study. It is important to note that the temperature response is person dependent and varies between volunteers between 0.2 and $0.95{ }^{\circ} \mathrm{C}$ in case of flight mode operation and from 0.5 to $1.25{ }^{\circ} \mathrm{C}$ in case of normal mode operation. The average personal response in 
Table 1 Technical specifications of the Samsung Galaxy S3 smartphone used during the IR thermography investigation

\begin{tabular}{ll}
\hline Parameter & Value/description \\
\hline Model & GT-i9300 \\
GSM standard/MHz & 900 (also 850, 1800,1900 available) \\
SAR/W kg & Head: $0.342 / \mathrm{W} \mathrm{kg}^{-1}$ \\
& Body: $0.547 / \mathrm{W} \mathrm{kg}^{-1}$ \\
Type & Touch screen $($ no keyboard) \\
Dimension $($ height $\times$ width $\times$ depth)/mm & $136.60 \times 70.60 \times 8.60$ \\
Weight/g & 133.00 \\
Battery & Li-Ion $2100 / \mathrm{mAh}$ \\
Processor & Samsung exynos 4412 \\
& Processor timer: $1.40 / \mathrm{GHz}$ \\
Available on the EU market & Core numbers: 4 \\
\hline
\end{tabular}

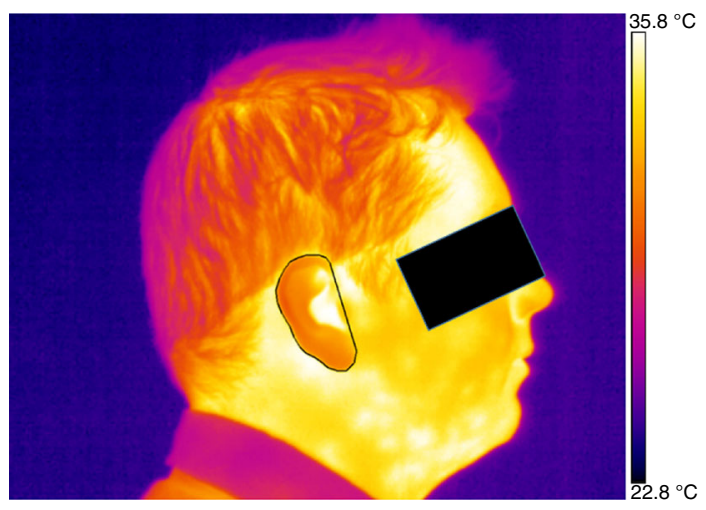

Fig. 1 Auricle region analysis carried out for one of the male volunteers. The outline of the auricle region was manually selected using the ThermaCAM Researcher Pro 2.10 software. The black patch in the picture is added to protect the identity of the volunteer and does not represent any thermal data

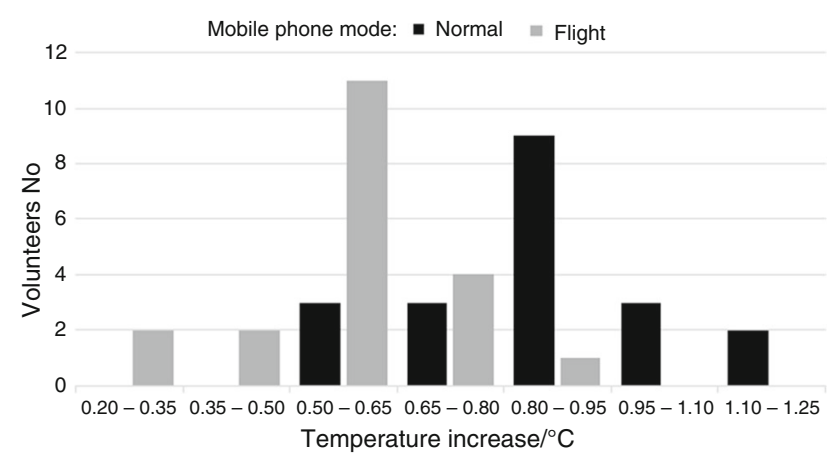

Fig. 2 Distribution of temperature increase immediately after a 5 min phone call in both normal mode (normal) and flight mode (flight)

temperature change is $0.83 \pm 0.04$ and $0.55 \pm 0.04{ }^{\circ} \mathrm{C}$ for normal and flight modes of operation, respectively. Our results point out the fact that temperature increase due to smartphone use is a combined effect of contact heat transfer through conduction caused by the basic non-microwave-related activity of the phone and the absorption of the radiofrequency electromagnetic radiation. The nonmicrowave-related activity can comprise of the temperature rise due to skin contact of the mobile phone during the use as well as the conduction of heat generated by, mainly, the battery, which sustained the basis operation mode without any microwave-related activity.

Kargel [23] has found that ear temperature could increase between 1.2 and $2.3{ }^{\circ} \mathrm{C}$ after $35 \mathrm{~min}$ phone call in contact (normal mode, SAR 1.26 W kg${ }^{-1}$ ). Lahiri et al. [24] found a temperature rise between 1.2 (SAR $0.83 \mathrm{~W} \mathrm{~kg}^{-1}$, battery capacity $800 \mathrm{~mA} \mathrm{~h}$ ) and $1.8{ }^{\circ} \mathrm{C}\left(\mathrm{SAR} 1.5 \mathrm{~W} \mathrm{~kg}^{-1}\right.$, battery capacity $1320 \mathrm{~mA} \mathrm{~h}$ ) after $40 \mathrm{~min}$ phone call in contact mode. The same authors have found a temperature rise of $0.2-0.4{ }^{\circ} \mathrm{C}$, which is similar to the lower limit of the flight mode temperature rise in our study. However, the mean temperature rise in our study is far higher than what has been reported by Lahiri et al. It has to be noted, however, that both Kargel and Lahiri et al. have conducted study on slightly smaller population, $n=6$ and 5 , respectively, than ours. In addition to this discrepancy in the investigated population, it should also notice the lower SAR $\left(0.34 \mathrm{~W} \mathrm{~kg}^{-1}\right)$ and higher battery capacity $(2100 \mathrm{~mA} \mathrm{~h})$ used in our study. The difference in the temperature rise $\left(0.28{ }^{\circ} \mathrm{C}\right)$ between the flight mode operation $\left(0.55^{\circ} \mathrm{C}\right)$ and the normal mode operation $\left(0.83{ }^{\circ} \mathrm{C}\right)$ may also point to the fact that $34 \%$ of the temperature rise can actually come from radiofrequency activity. This is comparable to the finding of Taurisano and Vorst [57] that about $40-45 \%$ of temperature rise on skin can actually be related to radiofrequency activity.

\section{IR thermography of the persistence of temperature change in auricle region after a short call (5 $\mathrm{min})$}

Temperature rise in body due to mobile phone is transient as the body homeostasis would always try to restore its thermal equilibrium. The thermal effect is also cumulative, 
and most authors in the literature now agree that the biological effect of mobile phones should be considered over a 10 years' time period. This means that both short- and long-duration use of mobile phones should be considered as contributors to such accumulation. Surprisingly, literature seldom discusses short-duration calls and how body restores the temperature with respect to time after the use of phones for such duration. Figure 3 shows the time-dependent mean temperature changes of auricle region of women, man, and the whole population in two alternative phone modes. Interestingly, even a short $5 \mathrm{~min}$ use of smartphones in contact can take a long time for the body to restore its thermal equilibrium. This persistence of the rise in temperature varies between male and female as well as between phone modes. In case of normal mode, the mean temperature increase immediately after a 5 min call was $0.78 \pm 0.06{ }^{\circ} \mathrm{C}$ for women and $0.87 \pm 0.06{ }^{\circ} \mathrm{C}$ for men. In flight mode, the rise was $0.49 \pm 0.05^{\circ} \mathrm{C}$ and $0.60 \pm 0.04{ }^{\circ} \mathrm{C}$ for women and men, respectively.

Results of statistical analyses depicted in Tables 2-7 at the confidence level of $95 \%$ show that independent of the operation mode and gender, the temperature changes after 5 min phone calls are statistically significant, even after $60 \mathrm{~min}$. Having in mind the thermal sensitivity of the camera $\left(50 \mathrm{mK}\right.$ at $\left.30{ }^{\circ} \mathrm{C}\right)$, we can define a restoration time that the body takes to return back to its original body temperature within a $0.05{ }^{\circ} \mathrm{C}$ temperature difference with respect to the original temperature at the start of the experiment (i.e., before the smartphone use commenced). This cutoff time can be found from the mean temperature difference columns in Tables 2-7. In general, the body takes nearly $60 \mathrm{~min}$ to restore its temperature.

Also, in normal mode after $60 \mathrm{~min}$, the mean temperature difference in women $\left(0.045{ }^{\circ} \mathrm{C}\right.$, Table 4$)$ and men $\left(0.044{ }^{\circ} \mathrm{C}\right.$, Table 5) case is similar. This is despite a higher mean temperature difference in men $\left(0.873{ }^{\circ} \mathrm{C}\right)$ compared to women $\left(0.778{ }^{\circ} \mathrm{C}\right)$ just after phone conversation. In the flight mode operation for men, temperature is restored slightly quicker (between 50 and $60 \mathrm{~min}$, Table 7) than in women (nearly $60 \mathrm{~min}$, Table 6). While such findings are interesting within the purview that the effect on temperature rise is relatively small $\left(\sim 0.12{ }^{\circ} \mathrm{C}\right)$ and short (duration around $10 \mathrm{~min}$ ) due to merely holding the phone in contact with ear, further study is required to determine the effect of pressure and the gender dimension as man could exert higher contact pressure than women.

\section{Smartphone thermal response test}

The smartphone used in the study (Samsung Galaxy S3) is equipped with a lithium-ion battery with a capacity of $2100 \mathrm{~mA} \mathrm{~h}$. Thermal analysis carried out before experiment showed that the rest temperature of the smartphone is $24.6{ }^{\circ} \mathrm{C}$ (Table 8 and Fig. 4). After 5 min use in normal mode, the temperature reached $26.4{ }^{\circ} \mathrm{C}$ with a total temperature difference of $1.8^{\circ} \mathrm{C}$. The faster temperature growth was observed during the first min of call $\left(1.2^{\circ} \mathrm{C}\right)$.

The warmest part of the smartphone is its processor, which is located on the back lower side. The observed rest mean temperature of the processor was $25.0^{\circ} \mathrm{C}$, but after the phone use, it increased to reach $28.5^{\circ} \mathrm{C}$. The temperature growth during the first min was $2.9^{\circ} \mathrm{C}$.

\section{Significance of the small-scale human examination}

Our small-scale investigation of smartphone heating of human auricle regions highlights the importance of
Fig. 3 Mean temperature of auricle changes during the experiment phases for whole population, women, man, and two alternative phone modes

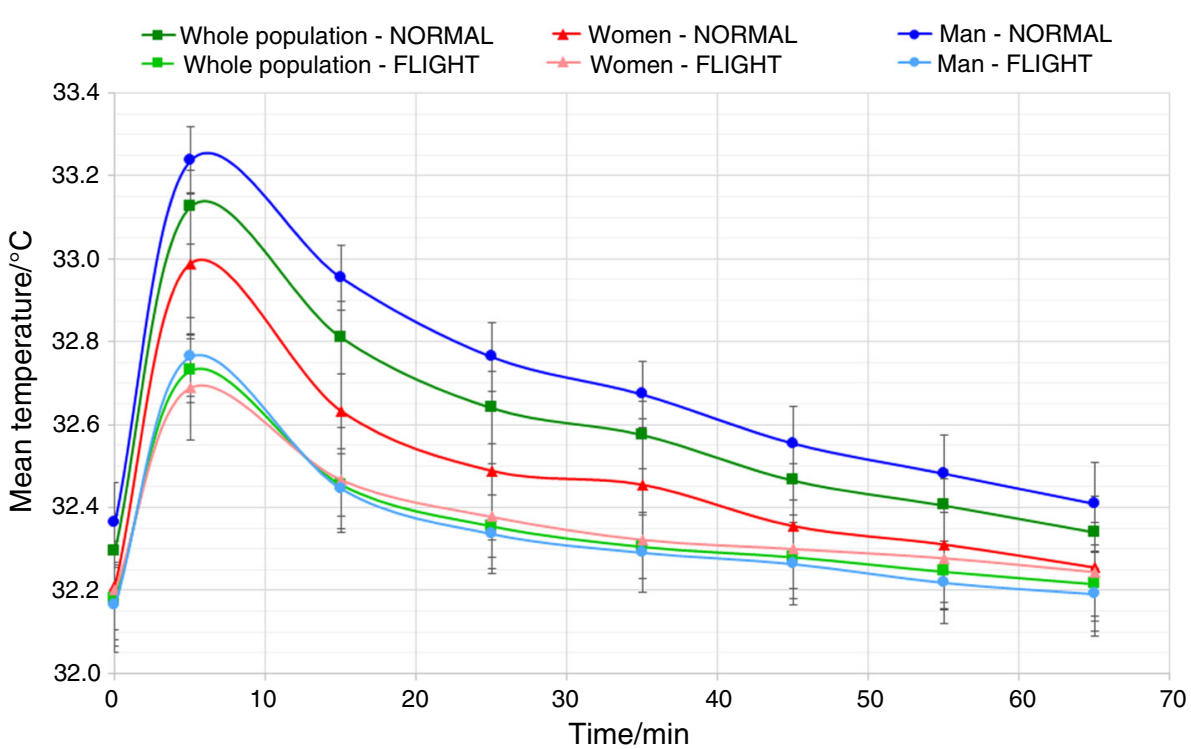


Table 2 Student's $t$ tests mean temperature changes before and after phone call performed in normal mode for all volunteers

\begin{tabular}{|c|c|c|c|c|c|c|c|}
\hline \multirow[t]{2}{*}{ Experiment phase } & \multirow[t]{2}{*}{ Mean difference } & \multirow[t]{2}{*}{$\mathrm{SD}$} & \multirow[t]{2}{*}{ Standard error mean } & \multicolumn{2}{|c|}{$95 \%$ confidence interval of the difference } & \multirow[t]{2}{*}{ Statistic $t$} & \multirow[t]{2}{*}{ Statistic $p$} \\
\hline & & & & Lower limit & Upper limit & & \\
\hline $0-5$ & -0.830 & 0.175 & 0.039 & -0.912 & -0.748 & -21.208 & $<0.001$ \\
\hline $0-10$ & -0.515 & 0.176 & 0.039 & -0.597 & -0.433 & -13.120 & $<0.001$ \\
\hline $0-20$ & -0.345 & 0.150 & 0.034 & -0.415 & -0.275 & -10.262 & $<0.001$ \\
\hline $0-30$ & -0.280 & 0.161 & 0.036 & -0.355 & -0.205 & -7.782 & $<0.001$ \\
\hline $0-40$ & -0.170 & 0.122 & 0.027 & -0.227 & -0.113 & -6.241 & $<0.001$ \\
\hline $0-50$ & -0.110 & 0.072 & 0.016 & -0.144 & -0.076 & -6.850 & $<0.001$ \\
\hline $0-60$ & -0.045 & 0.060 & 0.014 & -0.073 & -0.017 & -3.328 & 0.003 \\
\hline
\end{tabular}

Bold value indicates observed mean temperatures changes are eqaul or lower than thermal sensitivity of used $\mathrm{IR}$ camera $\left(50 \mathrm{mK}\right.$ at $\left.30{ }^{\circ} \mathrm{C}\right)$

Table 3 Student's $t$ tests mean temperature changes before and after phone call performed in flight mode for all volunteers

\begin{tabular}{|c|c|c|c|c|c|c|c|}
\hline \multirow[t]{2}{*}{ Experiment phase } & \multirow[t]{2}{*}{ Mean difference } & \multirow[t]{2}{*}{ SD } & \multirow[t]{2}{*}{ Standard error mean } & \multicolumn{2}{|c|}{$95 \%$ confidence interval of the difference } & \multirow[t]{2}{*}{ Statistic $t$} & \multirow[t]{2}{*}{ Statistic $p$} \\
\hline & & & & Lower limit & Upper limit & & \\
\hline $0-5$ & -0.550 & 0.147 & 0.033 & -0.619 & -0.481 & -16.744 & $<0.001$ \\
\hline $0-10$ & -0.275 & 0.145 & 0.032 & -0.343 & -0.207 & -8.503 & $<0.001$ \\
\hline $0-20$ & -0.175 & 0.116 & 0.026 & -0.229 & -0.121 & -6.723 & $<0.001$ \\
\hline $0-30$ & -0.125 & 0.097 & 0.022 & -0.170 & -0.080 & -5.784 & $<0.001$ \\
\hline $0-40$ & -0.100 & 0.079 & 0.018 & -0.137 & -0.063 & -5.627 & $<0.001$ \\
\hline $0-50$ & -0.065 & 0.081 & 0.018 & -0.103 & -0.027 & -3.577 & 0.002 \\
\hline $0-60$ & $-\mathbf{0 . 0 3 5}$ & 0.049 & 0.011 & -0.058 & -0.012 & -3.199 & 0.004 \\
\hline
\end{tabular}

Bold value indicates observed mean temperatures changes are eqaul or lower than thermal sensitivity of used $\mathrm{IR}$ camera $\left(50 \mathrm{mK}\right.$ at $\left.30{ }^{\circ} \mathrm{C}\right)$

Table 4 Student's $t$ tests mean temperature changes before and after phone call performed in normal mode for women population

\begin{tabular}{|c|c|c|c|c|c|c|c|}
\hline \multirow{2}{*}{ Experiment phase } & \multirow{2}{*}{ Mean difference } & \multirow{2}{*}{ SD } & \multirow{2}{*}{ Standard error mean } & \multicolumn{2}{|c|}{$95 \%$ confidence interval of the difference } & \multirow{2}{*}{ Statistic $t$} & \multirow{2}{*}{ Statistic $p$} \\
\hline & & & & Lower limit & Upper limit & & \\
\hline $0-5$ & -0.778 & 0.172 & 0.057 & -0.910 & -0.646 & -13.598 & $<0.001$ \\
\hline $0-10$ & -0.422 & 0.156 & 0.052 & -0.542 & -0.302 & -8.102 & $<0.001$ \\
\hline $0-20$ & -0.278 & 0.130 & 0.043 & -0.378 & -0.178 & -6.402 & $<0.001$ \\
\hline $0-30$ & -0.244 & 0.188 & 0.063 & -0.389 & -0.100 & -3.904 & 0.005 \\
\hline $0-40$ & -0.144 & 0.133 & 0.044 & -0.247 & -0.042 & -3.250 & 0.012 \\
\hline $0-50$ & -0.100 & 0.071 & 0.024 & -0.154 & -0.046 & -4.243 & 0.003 \\
\hline $0-60$ & -0.044 & 0.073 & 0.024 & -0.100 & -0.011 & -1.835 & 0.034 \\
\hline
\end{tabular}

Bold value indicates observed mean temperatures changes are eqaul or lower than thermal sensitivity of used $\mathrm{IR}$ camera $\left(50 \mathrm{mK}\right.$ at $\left.30{ }^{\circ} \mathrm{C}\right)$

studying short-duration use of smartphones as well as longer duration use. As it has been emphasized in the literature, thermal effects from mobile phone use are cumulative. Our results show that even short-term use of mobile phone can be a significant contributor to the overall cumulative effect of radiation dose in human. In particular, accumulation of radiation in the near skull region can lead to pathology formation such as brain tumors or neurobehavioral problems in the long perspective.

It was also found that the temperature rise can be contributed from both radiofrequency activity and non-radiofrequency activity. For the latter, we suspect that the battery capacity can be a strong contributory factor. This makes smartphones more prone to heating human tissues in contact as there is a trend in moving toward lower SAR and 
Table 5 Student's $t$ tests mean temperature changes before and after phone call performed in normal mode for men population

\begin{tabular}{|c|c|c|c|c|c|c|c|}
\hline \multirow[t]{2}{*}{ Experiment phase } & \multirow[t]{2}{*}{ Mean difference } & \multirow[t]{2}{*}{ SD } & \multirow[t]{2}{*}{ Standard error mean } & \multicolumn{2}{|c|}{$95 \%$ confidence interval of the difference } & \multirow[t]{2}{*}{ Statistic $t$} & \multirow[t]{2}{*}{ Statistic $p$} \\
\hline & & & & Lower limit & Upper limit & & \\
\hline $0-5$ & -0.873 & 0.174 & 0.052 & -0.989 & -0.756 & -16.661 & $<0.001$ \\
\hline $0-10$ & -0.591 & 0.158 & 0.048 & -0.697 & -0.485 & -12.418 & $<0.001$ \\
\hline $0-20$ & -0.400 & 0.148 & 0.045 & -0.499 & -0.300 & -8.944 & $<0.001$ \\
\hline $0-30$ & -0.309 & 0.138 & 0.041 & -0.401 & -0.217 & -7.455 & $<0.001$ \\
\hline $0-40$ & -0.191 & 0.114 & 0.034 & -0.267 & -0.115 & -5.573 & $<0.001$ \\
\hline $0-50$ & -0.118 & 0.075 & 0.023 & -0.169 & -0.068 & -5.221 & $<0.001$ \\
\hline $0-60$ & -0.045 & 0.052 & 0.016 & -0.081 & -0.010 & -2.887 & 0.016 \\
\hline
\end{tabular}

Bold value indicates observed mean temperatures changes are eqaul or lower than thermal sensitivity of used $\mathrm{IR}$ camera $\left(50 \mathrm{mK}\right.$ at $\left.30{ }^{\circ} \mathrm{C}\right)$

Table 6 Student's $t$ tests mean temperature changes before and after phone call performed in flight mode for women population

\begin{tabular}{|c|c|c|c|c|c|c|c|}
\hline \multirow[t]{2}{*}{ Experiment phase } & \multirow[t]{2}{*}{ Mean difference } & \multirow[t]{2}{*}{$\mathrm{SD}$} & \multirow[t]{2}{*}{ Standard error mean } & \multicolumn{2}{|c|}{$95 \%$ confidence interval of the difference } & \multirow[t]{2}{*}{ Statistic $t$} & \multirow[t]{2}{*}{ Statistic $p$} \\
\hline & & & & Lower limit & Upper limit & & \\
\hline $0-5$ & -0.489 & 0.145 & 0.048 & -0.601 & -0.377 & -10.094 & $<0.001$ \\
\hline $0-10$ & -0.267 & 0.150 & 0.050 & -0.382 & -0.151 & -5.333 & 0.001 \\
\hline $0-20$ & -0.178 & 0.130 & 0.043 & -0.278 & -0.078 & -4.097 & 0.003 \\
\hline $0-30$ & -0.122 & 0.120 & 0.040 & -0.215 & -0.030 & -3.051 & 0.016 \\
\hline $0-40$ & -0.100 & 0.071 & 0.024 & -0.154 & -0.046 & -4.243 & 0.003 \\
\hline $0-50$ & -0.078 & 0.083 & 0.028 & -0.142 & -0.014 & -2.800 & 0.023 \\
\hline $0-60$ & -0.044 & 0.053 & 0.018 & -0.085 & -0.004 & -2.530 & 0.035 \\
\hline
\end{tabular}

Bold value indicates observed mean temperatures changes are eqaul or lower than thermal sensitivity of used $\mathrm{IR}$ camera $\left(50 \mathrm{mK}\right.$ at $\left.30{ }^{\circ} \mathrm{C}\right)$

Table 7 Student's $t$ tests mean temperature changes before and after phone call performed in flight mode for men population

\begin{tabular}{llllllll}
\hline Experiment phase & Mean difference & SD & Standard error mean & \multicolumn{2}{l}{$95 \%$ confidence interval of the difference } & Statistic $t$ & Statistic $p$ \\
\cline { 5 - 6 } & & & & Lower limit & Upper limit & \\
\hline $0-5$ & -0.600 & 0.134 & 0.040 & -0.690 & -0.510 & -14.832 & $<0.001$ \\
$0-10$ & -0.282 & 0.147 & 0.044 & -0.380 & -0.183 & -6.354 & $<0.001$ \\
$0-20$ & -0.173 & 0.110 & 0.033 & -0.247 & -0.099 & -5.190 & $<0.001$ \\
$0-30$ & -0.127 & 0.079 & 0.024 & -0.180 & -0.074 & -5.369 & $<0.001$ \\
$0-40$ & -0.100 & 0.089 & 0.027 & -0.160 & -0.040 & -3.708 & 0.004 \\
$0-50$ & $-\mathbf{0 . 0 5 5}$ & 0.082 & 0.025 & -0.110 & -0.001 & -2.206 & 0.029 \\
$0-60$ & -0.027 & 0.047 & 0.014 & -0.059 & -0.004 & -1.936 & 0.041 \\
\hline
\end{tabular}

Bold value indicates observed mean temperatures changes are eqaul or lower than thermal sensitivity of used IR camera $\left(50 \mathrm{mK}\right.$ at $\left.30{ }^{\circ} \mathrm{C}\right)$

higher battery capacity smartphones due to their increased non-telephonic use.

Also, the gender dimension is a new aspect of our study and has not been received much attention in the literature. This is interesting and probably deserves further investigation in the future.

Moreover, there is a personalized dimension of the thermal response to smartphones (Fig. 2), where IR thermography can be successfully used due to its high sensitivity and non-contact measurement ability in a large field of view. Kargel [23] and Lahiri et al. [24] have also used IR thermography in their investigations albeit to a much smaller population of volunteers. The use of thermography is highly advantageous in direct measurements of thermal distribution and can provide valuable input to computer simulation that uses surface temperature and SAR values in calculating tumor formation probability in response to thermal effect. IR thermography has been 
Table 8 Temperature measurements of the backside of the Samsung Galaxy S3 smartphone during a 5 min use in normal mode

\begin{tabular}{lllll}
\hline Time/min & Mean temperature $/{ }^{\circ} \mathrm{C}$ & Mean temperature increase $/{ }^{\circ} \mathrm{C}$ & Maximum temperature $/{ }^{\circ} \mathrm{C}$ & Maximum temperature increase $/{ }^{\circ} \mathrm{C}$ \\
\hline 0 & 24.6 & - & 25.0 & - \\
1 & 25.8 & 1.2 & 27.9 & 2.9 \\
2 & 26.1 & 0.3 & 28.1 & 0.2 \\
3 & 26.3 & 0.2 & 28.3 & 0.2 \\
4 & 26.4 & 0.1 & 28.4 & 0.1 \\
5 & 26.4 & 0 & 28.5 & 0.1 \\
\hline
\end{tabular}

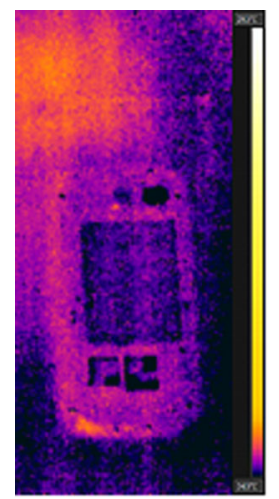

Before

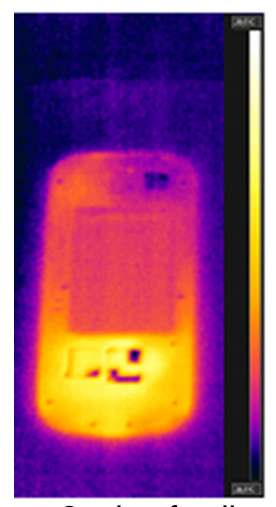

3 min of call

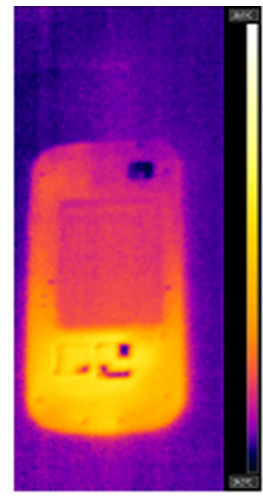

$1 \mathrm{~min}$ of call

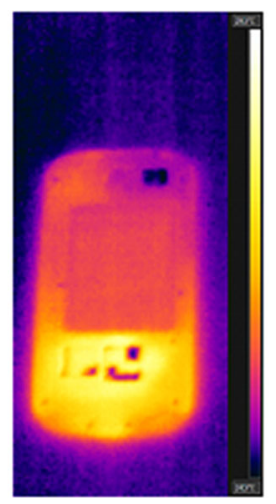

4 min of call

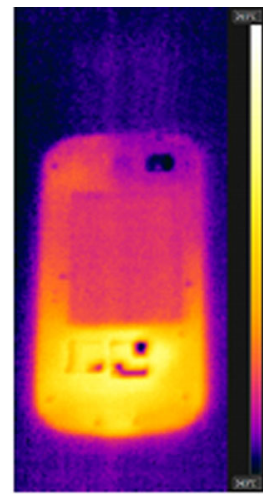

2 min of call

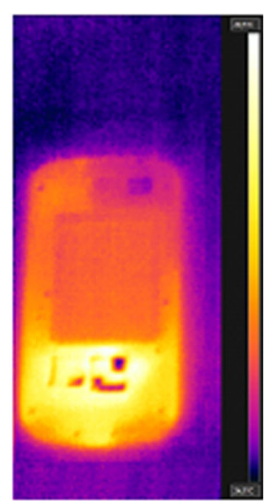

5 min of call
Fig. 4 Thermal images of the backside of the Samsung Galaxy 3 smartphone before and during 5 min phone call. The temperature scales have been normalized for all thermographs shown here for quantitative data given in Table 8

widely used in detecting breast cancer and malignant melanoma and can be possibly extended to directly linking thermal effects in pathogenesis pathway to pathology detection. This way, thermal imaging can also provide valuable insights to the prevention of such pathology development in a personalized way at the general practitioners and hospital outpatient services instead of referring patients or subjects to the inpatient radiology services.

\section{Conclusions}

We have found that there are statistically significant differences between mean temperatures of the auricle regions in these subjects before and immediately after the use of the smartphone, independent of whether radiofrequency communication was on (normal mode) or off (flight mode). The increase in tissue temperature was caused by a combined effect of conductive heat transfer caused by the basic non-microwave-related activity of the smartphone and the absorption of the microwave.

Furthermore, the thermal effect was observed even after $1 \mathrm{~h}$ of the short use of the smartphone. The transient temperature change in tissues due to smartphone use can contribute to the cumulative thermal effects, and both short- and long-duration use of smartphones should be considered in future epidemiological studies. The smallgroup investigation indicates that smartphone use can have a gender dimension in the thermal response, which merits further large-group investigation. This study also showed the strengths of IR thermography in direct quantitative analyses of temperature changes related to smartphone usage. This can lead to many quantitative large-group investigations in the future.

Finally, we can summarize the following observations from our investigation:

- There are statistically significant differences between mean temperatures of the auricle before and after phone call—independently on applied mode. It means that for the thermal effect are responsible both non-microwave mobile phone activity and microwave mobile phone activity.

- The mean superficial temperature of the auricle region just after 5 min phone call in case of normal mode is higher $\left(0.83 \pm 0.04{ }^{\circ} \mathrm{C}\right)$, whereas for flight mode is slightly lower $\left(0.55 \pm 0.04{ }^{\circ} \mathrm{C}\right)$.

- The comparison of the results obtained for women and men shows that men accumulate more heat than women; however, the thermal effect is marginally shorter. For women, the mean temperature increase after $5 \mathrm{~min}$ phone call in normal mode is 
$0.78 \pm 0.06{ }^{\circ} \mathrm{C}$, whereas in flight mode, it is $0.49 \pm 0.05{ }^{\circ} \mathrm{C}$. For men, mean temperature increase is $0.87 \pm 0.06{ }^{\circ} \mathrm{C}$ for normal mode and $0.60 \pm 0.04{ }^{\circ} \mathrm{C}$ for flight mode.

- After $5 \mathrm{~min}$ phone call in normal mode, the temperature of the backside of the smartphone changes from $24.6{ }^{\circ} \mathrm{C}$ till $26.4{ }^{\circ} \mathrm{C}$, which gives total difference $1.8^{\circ} \mathrm{C}$. The faster temperature growth is observed during the first min of call $\left(1.2^{\circ} \mathrm{C}\right)$.

Acknowledgements The study was conducted thanks to the statutory fund from the Polish Ministry of Science and Higher Education (MNISW), which is gratefully acknowledged by the authors of this research.

Open Access This article is distributed under the terms of the Creative Commons Attribution 4.0 International License (http://crea tivecommons.org/licenses/by/4.0/), which permits unrestricted use, distribution, and reproduction in any medium, provided you give appropriate credit to the original author(s) and the source, provide a link to the Creative Commons license, and indicate if changes were made.

\section{References}

1. Mobile phone, smartphone usage varies globally. 2016. https:// www.emarketer.com/Article/Mobile-Phone-Smartphone-UsageVaries-Globally/1014738. Accessed 31 July 2017.

2. Cleveland RFS, David MU, Jerry L. Evaluating compliance with FCC guidelines for human exposure to radiofrequency electromagnetic fields. OST Bull. 1997;65:97-101.

3. Siauve N, Scorretti R, Burais N, Nicolas L, Nicolas A. Electromagnetic fields and human body: a new challenge for the electromagnetic field computation. COMPEL. 2003;22(3):457-69.

4. Habash RWY. Bioeffects and therapeutic applications of electromagnetic energy. Boca Raton: CRC Press; 2008.

5. Robertson V, Ward A, Low J, Reed A. Electrotherapy explained, principles and practice. 4th ed. Amsterdam: Elsevier; 2006.

6. Neumann E, Schaefer-Ridder M, Wang Y, Hofschneider PH. Gene transfer into mouse lyoma cells by electroporation in high electric fields. EMBO J. 1982;1:841-5.

7. Wezgowiec J, Kulbacka J, Kotulska M. Electroporation in modern oncology. In: Tofail SAM, Bauer J, editors. Electrically active materials for medical devices. London: Imperial College Press; 2016. p. 473-90.

8. Lai H, Singh NP. Single- and double-strand DNA breaks in rat brain cells after acute exposure to radiofrequency electromagnetic radiation. Int J Radiat Biol. 1996;69:513-21.

9. Blank M, Goodman R. Electromagnetic fields may act directly on DNA. J Cell Biochem. 1999;75:369-74.

10. De Iuliis GN, Newey RJ, King BV, Aitken RJ. Mobile phone radiation induces reactive oxygen species production and DNA damage in human spermatozoa in vitro. PLoS ONE. 2009;4(7):e6446.

11. Panagopoulos DJ. Analyzing the health impacts of modern telecommunications microwaves. Adv Med Biol. 2011;17:1-55.

12. Simon HU, Haj-Yehia A, Levi-Schaffer F. Role of reactive oxygen species (ROS) in apoptosis induction. Apoptosis. 2000;5:415-8.

13. Kesari KK, Kumar S, Behari J. Effects of radiofrequency electromagnetic wave exposure from cellular phones on the reproductive pattern in male wistar rats. Appl Biochem Biotechnol. 2011;164(4):546-59.

14. Laurence JA, French PW, Lindner RA, McKenzie DR. Biological effects of electromagnetic fields-mechanisms for the effects of pulsed microwave radiation on protein conformation. $\mathrm{J}$ Theor Biol. 2000;206:291-8.

15. Ha BY. Stabilization and destabilization of cell membranes by multivalent ions. Phys Rev E Stat Nonlin Soft Matter Phys. 2001;64:051902:1-5.

16. Blackman CF, Benane SG, Kinney LS, Joines WT, House DE. Effects of ELF fields on calcium-ion efflux from brain tissue in vitro. Radiat Res. 1982;92:510-20.

17. Hamada AJ, Singh A, Agarwal A. Cell phones and their impact on male fertility: fact or fiction. Open Reprod Sci J. 2011;5:125-37.

18. Adair ER, Adams BW, Akel GM. Minimal changes in hypothalamic temperature accompany microwave-induced alteration of thermoregulatory behavior. Bioelectromagnetics. 1984;5:13-30.

19. Boerner E, Bauer J, Kuczkowska M, Podbielska H, Ratajczak B. Comparison of the skin surface temperature on the front of thigh after application of combined red-IR radiation and diadynamic currents executed in a different sequence. J Therm Anal Calorim. 2015;120(1):921-8.

20. Tofail SAM, Bauer J. Electrically polarized biomaterials. Adv Mater. 2016;28(27):5470-84.

21. Tofail SAM, Bauer J, editors. Electrically active materials for medical devices. London: Imperial College Press; 2016.

22. Tahvanainen $K$, Nino $J$, Halonen $P$, Kuusela $T$, Alanko $T$, Laitinen T, Lansimies E, Hietanen M, Lindholm H. Effects of cellular phone use on ear canal temperature measured by NTC thermistors. Clin Physiol Funct Imaging. 2007;27:162-72.

23. Kargel C. Infrared thermal imaging to measure local temperature rises caused by handheld mobile phones. IEEE Trans Instrum Meas. 2005;54:1513-9.

24. Lahiri BB, Bagavathiappan S, Soumya C, Jayakumar T, Philip J. Infrared thermography based studies on mobile phone induced heating. Infrared Phys Technol. 2015;71:242-51.

25. Khurana VG, Teo C, Kundi M, Hardell L, Carlberg M. Cell phones and brain tumors: a review including the long-term epidemiologic data. Surg Neurol. 2009;72:205-15.

26. Dreyer NA, Loughlin JE, Rothman K. Cause-specific mortality in cellular telephone users. JAMA. 1999;282(19):1814-6.

27. Schüz J, Jacobsen R, Olsen JH, Boice JD, McLaughlin JK, Johansen C. Cellular telephone use and cancer risk: update of a nationwide Danish cohort. JNCI. 2006;98:1707-13.

28. Deltour I, Auvinen A, Feychting M, Johansen C, Klaeboe L, Sankila R, Schüz J. Mobile phone use and incidence of glioma in the Nordic countries 1979-2008: consistency check. Epidemiology. 2012;23(2):301-7.

29. Little MP, Rajaraman P, Curtis RE, Devesa SS, Inskip PD, Check DP, Linet MS. Mobile phone use and glioma risk: comparison of epidemiological study results with incidence trends in the United States. BMJ. 2012;344:e1147.

30. Schoemaker MJ, Swerdlow AJ, Ahlbom A, Auvinen A, Blaasaas KG, Cardis E, Christensen HC, Feychting M, Hepworth SJ, Johansen C, Klaeboe L, Lönn S, McKinney PA, Muir K, Raitanen J, Salminen T, Thomsen J, Tynes T. Mobile phone use and risk of acoustic neuroma: results of the Interphone case-control study in five North European countries. Br J Cancer. 2005;93:842-8.

31. Hepworth SJ, Schoemaker MJ, Muir KR, Swerdlow AJ, Tongeren MJ, McKinney PA. Mobile phone use and risk of glioma in adults: case-control study. BMJ. 2006;332:883.

32. Prasad M, Kathuria P, Nair P, Kumar A, Prasad K. Mobile phone use and risk of brain tumours: a systematic review of association between study quality, source of funding, and research outcomes. Neurol Sci. 2017;38(5):797-810. 
33. International Agency for Research on Cancer (IARC). In: IARC classifies radiofrequency electromagnetic fields as possibility carcinogenic to humans. 2013. http://monographs.iarc.fr/ENG/ Classification/. Accessed 31 July 2017.

34. Kim KH, Kabir E, Jahan SA. The use of cell phone and insight into its potential human health impacts. Environ Monit Assess. 2016;188:221-32.

35. Abdel-Rassoul G, El-Fateh OA, Salem MA, Michael A, Farahat F, El-Batanouny E, Salem E. Neurobehavioral effects among inhabitants around mobile phone base stations. Neurotoxicology. 2007;28(2):434-40.

36. Koivisto M, Krause CM, Revonsuo A, Laine M, Hamalainen H. The effects of electromagnetic field emitted by GSM phones on working memory. NeuroReport. 2000;22:1641-3.

37. Koivisto M, Revonsuo A, Krause CM, Haarala C, Sillanmaki L, Laine M, Hamalainen $\mathrm{H}$. Effects of $902 \mathrm{MHz}$ electromagnetic field emitted by cellular telephones on response times in humans. NeuroReport. 2000;11:413-5.

38. Krause CM, Haarala C, Sillanmaki L, Koivisto M, Alanko K, Revonsuo A, Laine M, Hamalainen H. Effects of electromagnetic field emitted by cellular phones on the EEG during an auditory memory task: a double blind replication study. Bioelectromagnetics. 2004;25:33-40.

39. Krause CM, Sillanmaki L, Koivisto M, Haggqvist A, Saarela C, Revonsuo A, Laine M, Hamalainen H. Effects of electromagnetic fields emitted by cellular phones on the electroencephalogram during a visual working memory task. Int $\mathrm{J}$ Radiat Biol. 2000;76:1659-67.

40. Borbely AA, Huber R, Graf T, Fuchs B, Gallmann E, Achermann P. Pulsed high-frequency electromagnetic field affects human sleep and sleep electroencephalogram. Neurosci Lett. 1999;275:207-10.

41. Huber R, Treyer V, Borbely AA, Schuderer J, Gottselig JM, Landolt HP, Werth E, Berthold T, Kuster N, Buck A, Achermann P. Electromagnetic fields, such as those from mobile phones, alter regional cerebral blood flow and sleep and waking EEG. J Sleep Res. 2002;11:289-95.

42. Mann K, Röschke J. Effects of pulsed high-frequency electromagnetic fields on human sleep. Neuropsychobiology. 1996;33:41-7.

43. Oftedal G, Wilen J, Sandstrom M, Mild KH. Symptoms experienced in connection with mobile phone use. Occup Med. 2000;50:237-45.

44. Acharya JP, Acharya I, Waghrey D. A study on some psychological health effects of cell-phone usage amongst college going students. Int J Med Res Health Sci. 2013;2(3):388-94.
45. Goyal AK. Studies on phantom vibration and ringing syndrome among postgraduate students. Indian $\mathrm{J}$ Commun Health. 2015;27(1):35-40.

46. Morgan LL, Kesari S, Lee Davis D. Why children absorb more microwave radiation than adults: The consequences. JMAU. 2014;2(4):197-204.

47. Christ A, Gosselin MC, Christopoulou M, Kuhn S, Kuster N. Age-dependent tissue-specific exposure of cell phone users. Phys Med Biol. 2010;55:1767-83.

48. Agarwal A, Deepinder F, Sharma RK, Ranga G, Li J. Effect of cell phone usage on semen analysis in men attending infertility clinic: an observational study. Fertil Steril. 2008;89:124-8.

49. European Association of Thermology. 2016. http://www.eur opeanthermology.com/cms32/index.php?GUIDELINES. Accessed 1 Dec 2016.

50. Fernández-Cuevas I, Bouzas Marins JC, Arnáiz Lastras J, Gómez Carmona PM, Piñonosa Cano S, García-Concepción MA, SilleroQuintana M. Classification of factors influencing the use of infrared thermography in humans: a review. Infrared Phys Technol. 2015;71:28-55.

51. Rok T, Rokita E, Tatoń G, Guzik Śliwa T. Thermographic imaging as alternative method in allergy diagnosis. J Therm Anal Calorim. 2016. https://doi.org/10.1007/s10973-016-5676-3.

52. Cholewka A, Kasprzyk T, Stanek A, Sieron-Stołtny K, Drzazga Z. May thermal imaging be useful in cyclist endurance tests? J Therm Anal Calorim. 2016. https://doi.org/10.1007/s10973015-4662-5.

53. Cholewka A, Kajewska J, Kawecki M, Sieroń-Stołtny K, Stanek A. How to use thermal imaging in venous insufficiency. J Therm Anal Calorim. 2017. https://doi.org/10.1007/s10973-017-6141-7.

54. Cholewka A, Stanek A, Wójcik M, Sieroń-Stołtny K, Drzazga Z. Does local cryotherapy improve thermal diagnosis similar to whole-body cryotherapy in spinal diseases? J Therm Anal Calorim. 2016. https://doi.org/10.1007/s10973-016-5453-3.

55. Boerner E, Bauer J, Ratajczak B, Dereń E, Podbielska H. Application of thermovision for analysis of superficial temperature distribution changes after physiotherapy-comparison of infrared irradiation and cryotherapy. J Therm Anal Calorim. 2015. https://doi.org/10.1007/s10973-014-4026-6.

56. IBM trial download: SPSS Statistics Desktop 23.0. 2016. https:// www.ibm.com/analytics/us/en/technology/predictive-analytics/ \#products. Accessed 10 Dec 2016.

57. Taurisano MD, Vorst AV. Experimental thermographic analysis of thermal effects induced on a human head exposed to $900 \mathrm{MHz}$ fields of mobile phones. IEEE Trans Microw Theory Tech. 2000;48:2022-32. 